\title{
Effect of defect content on the unipolar resistive switching characteristics of ZnO thin film memory devices
}

\author{
Feng Zhang a,b, Xiaomin $\mathrm{Li}^{\mathrm{a}, *}$, Xiangdong Gao ${ }^{\mathrm{a}}$, Liang $\mathrm{Wu}^{\mathrm{a}, \mathrm{b}}$, Fuwei Zhuge ${ }^{\mathrm{a}, \mathrm{b}}$, Qun Wang ${ }^{\mathrm{a}}$, \\ Xinjun Liu ${ }^{c}$, Rui Yang ${ }^{\mathrm{d}}$, Yong $\mathrm{He}^{\mathrm{a}, \mathrm{b}}$ \\ a State Key Laboratory of High Performance Ceramics and Superfine Microstructures, Shanghai Institute of Ceramics, Chinese Academy of Sciences, Shanghai 200050, People's \\ Republic of China \\ ${ }^{\mathrm{b}}$ Graduate School of Chinese Academy of Science, Beijing 100039, People's Republic of China \\ ${ }^{\mathrm{c}}$ Department of Materials Science and Engineering, Gwangju Institute of Science and Technology (GIST), 261 Cheomdan-gwagiro (Oryong-dong), Buk-gu, Gwangju 500-712, \\ Republic of Korea \\ d International Center for Materials Nanoarchitectonics (MANA), National Institute for Materials Science (NIMS), 1-1 Tsukuba, Ibaraki 305-0044, Japan
}

\section{A R T I C L E I N F O}

\section{Article history:}

Received 28 November 2011

Received in revised form

21 March 2012

Accepted 27 April 2012

by M. Wang

Available online 3 May 2012

Keywords:

A. Zinc oxide

A. Thin film

D. Resistive switching

\begin{abstract}
A B S T R A C T
In this study, unipolar resistive switching (URS) characteristics in ZnO thin film memory devices were systematically investigated with variable defect content. ZnO films displayed typically URS behavior while oxygen-deficient $\mathrm{ZnO}_{1-x}$ films did not show resistive switching effects. The devices with two intentional Ohmic interfaces still show URS. These results show that appearance of URS behavior can be dominated by initial oxygen vacancy content in $\mathrm{ZnO}$ thin films. Modest increase in oxygen vacancy content in $\mathrm{ZnO}$ films will lead to forming-free and narrower distributions of switching parameters (set and reset voltage, high and low resistance states). It indicates that controlling the initial oxygen vacancy content was an effective method to enhance the URS performance.
\end{abstract}

(c) 2012 Elsevier Ltd. All rights reserved.

\section{Introduction}

Resistance random access memory (RRAM) is considered as a very promising candidate for next generation nonvolatile memory due to its fast switching speed, high density, and low power consumption [1,2]. External electrical bias or pulse induced reversible resistive switching effect is generally utilized in these devices $[1,3,4]$. With the dependence on the polarity of applied voltage, the resistive switching effect is classified into unipolar and bipolar resistive switching behaviors (URS and BRS) [4,5]. Compared with BRS behavior, the URS exhibits faster reset speed, larger OFF/ON ratio, and require simpler peripheral circuit $[6,7]$. Up to now, resistive switching effect has been reported in many perovskite oxides and binary metal oxides thin films [4]. Interestingly, almost all the reported resistive switching oxides could display URS behavior, even previously reported BRS multinary oxides (LCMO [8], PCMO [9], and STO [10]). Lee et al.. [11] also developed a material-independent scaling theory to explain the URS behavior. Although the URS may be a material-independent behavior, few works focused on the determining factor for the URS behavior.

It has been widely accepted that URS behavior was attributed to the rupture and recovery of percolating defect filament initialized by

\footnotetext{
*Corresponding author. Tel.: +8621 52412554; fax: +862152413122.

E-mail address: lixm@mail.sic.ac.cn (X. Li).
}

forming process [12-15], which was also well simulated by the random circuit breaker model [7] with a defects network. It is reasonable that the defects forming the filament could be divided into the initial defects and new-generated defects in the forming process. Besides, both the interfacial state and the resistance state of the sandwich structure devices are related with the initial defect content $[4,16]$. So it is necessary to investigate the effect of the initial defect content on URS characteristics. For ZnO-based RRAM devices, $\mathrm{ZnO}$ is a typical n-type semiconductor owing to oxygen vacancy and interstitial zinc ion and many studies have indicated that electrons' hopping on oxygen vacancy filaments is responsible for its URS behaviors [17-20]. Based on above consideration, we systematically investigated the effect of initial oxygen vacancy content on URS characteristics of $\mathrm{ZnO}$ thin film memory devices. The results demonstrated that appropriate oxygen vacancy content in its initial state was a determining factor for the appearance of URS behavior, and control the initial oxygen vacancy content of $\mathrm{ZnO}$ films is an effective method for the improvement of the URS performance.

\section{Experimental details}

ZnO thin films were deposited by pulsed laser deposition (PLD) on $\mathrm{Pt} / \mathrm{Ti} / \mathrm{SiO}_{2} / \mathrm{Si}$ substrates at $200{ }^{\circ} \mathrm{C}$ using a ceramic $\mathrm{ZnO}$ target. For comparative investigation, three types of $\mathrm{ZnO}$ samples with 
different deposition condition were fabricated; Oxygen-deficient $\mathrm{ZnO}_{1-x}$ was deposited for 80 min under vacuum. Nearly stoichiometric $\mathrm{ZnO}$ thin films were deposited for 80 min under an oxygen partial pressure of $2 \mathrm{~Pa}$ and oxygen plasma was used for assisting growth. Stacked $\mathrm{ZnO}_{1-x} / \mathrm{ZnO} / \mathrm{ZnO}_{1-x}$ thin films were firstly deposited for 20 min under vacuum and then for 40 min under an oxygen partial pressure of $2 \mathrm{~Pa}$ (oxygen plasma), subsequently deposited for 20 min under vacuum. The thickness of $\mathrm{ZnO}_{1-x}, \mathrm{ZnO}$, and stacked $\mathrm{ZnO}_{1-x} / \mathrm{ZnO} / \mathrm{ZnO}_{1-x}$ thin films were all approximately $120 \mathrm{~nm}$. XPS measurements (Thermo Scientific ESCALAB 250) were performed in ultra-high vacuum with a base pressure of $10^{-10}$ mbar and were using the VG Avantage 4.53 software system. The measurement chamber is equipped with a monochromatic $\mathrm{Al}\left(K_{\alpha}\right)$ X-ray source providing photo with $h v=1486.6 \mathrm{eV}$ and a FLOOD GUN to avoid surface charging. Its energy resolution is $0.49 \mathrm{eV}$. In order to examine the chemical state of each element, the samples were etched by $\mathrm{Ar}+$ bombardment $\left(\sim 10^{-5} \mathrm{Torr}\right)$ with the energy of $1 \mathrm{kV}$ and a current of $1 \mu \mathrm{A}$. The position of the $\mathrm{C} 1 \mathrm{~s}$ peak was taken as a standard (with a bounding energy of $280.50 \mathrm{eV}$ ).

For electrical testing, $50 \mathrm{~nm}$-thick Pt top electrodes with a diameter of $100 \mu \mathrm{m}$ were deposited on these films by electron beam evaporation with a metal shadow mask. All the resistance values of initial state (before forming process, $R_{\text {initial }}$ ), high resistance state (HRS, $R_{\text {off }}$ ) and low resistance state (LRS, $R_{\text {on }}$ ) were measured at $0.01 \mathrm{~V}$. The current-voltage $(I-V)$ curves of these devices were examined by a Keithley 2410c source meter unit with the bottom electrodes being grounded.

\section{Results and disscussions}

Fig. 1(a) and (b) show the initial $I-V$ characteristics of $\mathrm{Pt} / \mathrm{ZnO}_{1-x} / \mathrm{Pt}$ devices and $\mathrm{Pt} / \mathrm{ZnO} / \mathrm{Pt}$ devices in their pristine states. The resistance values of the sandwich structure devices could be regarded as two interfacial resistances in series with bulk resistance of the films. The $\mathrm{Pt} / \mathrm{ZnO}_{1-x} / \mathrm{Pt}$ devices have a large leakage current with a low $R_{\text {initial }}$ of $11 \Omega$ and do not display any resistive switching behavior. The linear $I-V$ curve [Fig. 1(a)] indicates Ohmic contacts at both $\mathrm{Pt} / \mathrm{ZnO}_{1-x}$ interfaces. On the contrast, the $\mathrm{Pt} / \mathrm{ZnO} / \mathrm{Pt}$ devices show dual rectifying $I-V$ curve [Fig. 1(b)], revealing Schottky contacts at both Pt/ZnO interfaces. Typical URS behavior was observed, as shown in Fig. 1(c). The $R_{\text {initial }}$ of the $\mathrm{Pt} / \mathrm{ZnO} / \mathrm{Pt}$ devices was $3 \times 10^{6} \Omega$ and the forming process switched the device to a low LRS of $30 \Omega$. Then the URS behavior was observed.

In order to investigate the nature of different resistance states and the resistive switching for the $\mathrm{ZnO}$ and $\mathrm{ZnO}_{1-x}$ films, X-ray photoelectron spectroscopy (XPS) was employed to examine the chemical composition and the existence of defects. The film surface was etched for $5 \mathrm{~s}$ to avoid interference of surface absorbed oxygen. Fig. 2 shows the XPS spectra of $O$ 1s peak and its Gaussion fitting results for $\mathrm{ZnO}_{1-x}$ and $\mathrm{ZnO}$ thin films. O 1s of $\mathrm{ZnO}$ thin films were fitted by three Gaussian components at $\sim 529.7 \mathrm{eV}, \sim 530.5 \mathrm{eV}$ and $\sim 532.0 \mathrm{eV}[21,22] .532 .0 \mathrm{eV}$ is usually attributed to chemically absorbed oxygen at the surface. The component of lowest bounding energy at $529.7 \mathrm{eV}$ is associated with $\mathrm{O}^{2-}$ in $\mathrm{ZnO}$ structure. For $\mathrm{ZnO}$ films, $\mathrm{O}^{-2}$ content was increased compared with $\mathrm{ZnO}_{1-x}$ films. Approximate composition ( $\mathrm{Zn} / \mathrm{O}$ in at\%) of $\mathrm{ZnO}$ films was $51: 49$ while it was 58:42 in $\mathrm{ZnO}_{1-x}$ films. The component of medium bounding energy at $530.5 \mathrm{eV}$ is related to $\mathrm{O}^{2-}$ of oxygen deficiencies. Changes in the intensity of this component mainly connected in part to the variations in the content of oxygen vacancies. $\mathrm{ZnO}$ films exhibited a distinct reduction in the signal for oxygen vacancies. Considering $\mathrm{ZnO}$ was a typical n-type semiconductor owing to oxygen vacancies and interstitial zinc ion, all the interfacial and bulk resistances could be determined by the oxygen vacancy

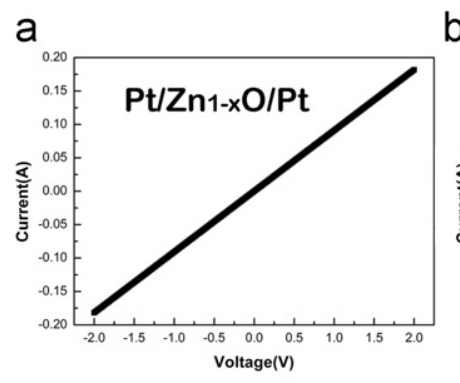

b

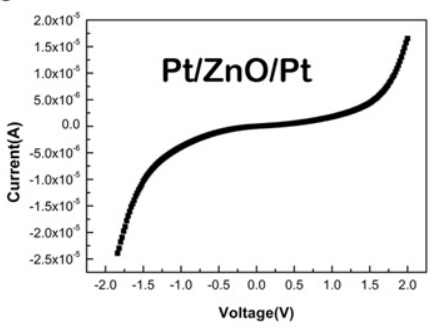

C

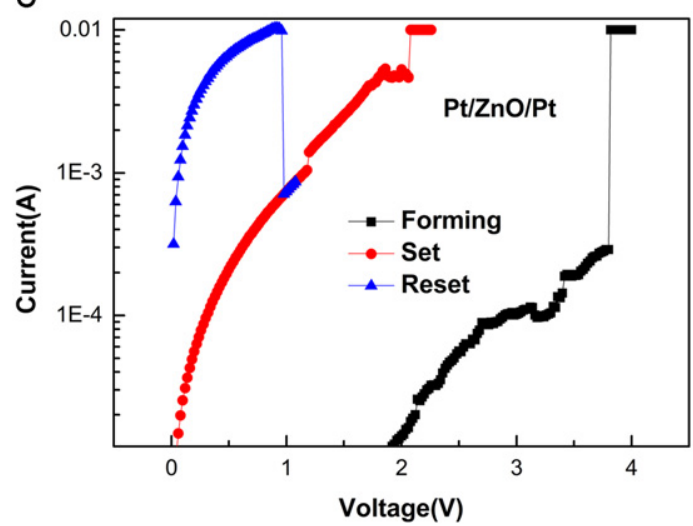

Fig. 1. (Color online) The $I-V$ curves of the (a) $\mathrm{Pt} / \mathrm{ZnO}_{1_{-x}} / \mathrm{Pt}$ device and (b) $\mathrm{Pt} / \mathrm{ZnO} /$ $\mathrm{Pt}$ device in their pristine states. (c) Forming and URS I-V curves for $\mathrm{Pt} / \mathrm{ZnO}_{1-x} / \mathrm{Pt}$ device.

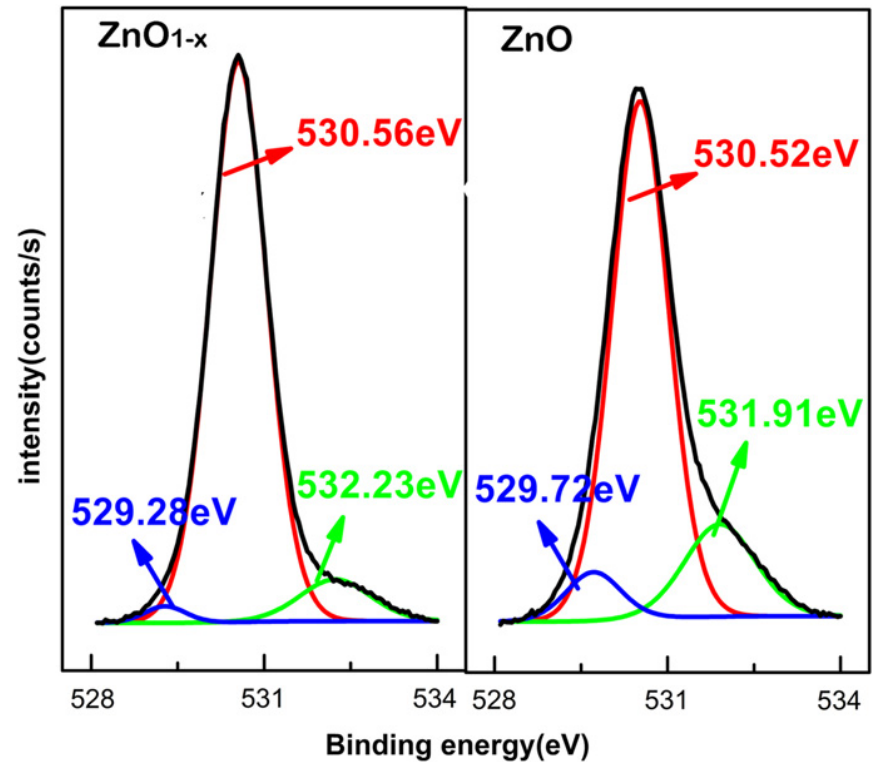

Fig. 2. (Color online) XPS spectra of $\mathrm{O} 1 \mathrm{~s}$ core levels for $\mathrm{ZnO}_{1-x}$ and $\mathrm{ZnO}$ thin films.

content [4]. For $\mathrm{Pt} / \mathrm{ZnO}_{1-x} / \mathrm{Pt}$ devices, it is clear that the large quantity of oxygen vacancies would eliminate the Schottky barrier $(\mathrm{Pt} / \mathrm{ZnO})$ and decreased the bulk resistance dramatically. The reduction in quantity of oxygen vacancies in $\mathrm{ZnO}$ films would increase the bulk resistance and cause the depletion layer wider, resulting in a large $R_{\text {initial }}$ and the dual rectifying $I-V$ curve.

Since $\mathrm{ZnO}$ films displayed typically URS behavior while $\mathrm{ZnO}_{1-x}$ films did not show any resistive switching effects, we could conclude that the initial oxygen vacancy content was a determining factor for appearance of URS behavior. Nevertheless, whether the Schottky interfaces in the Pt/ZnO/Pt devices play an essential for URS behavior remains unclear. In this regards, we further 
a

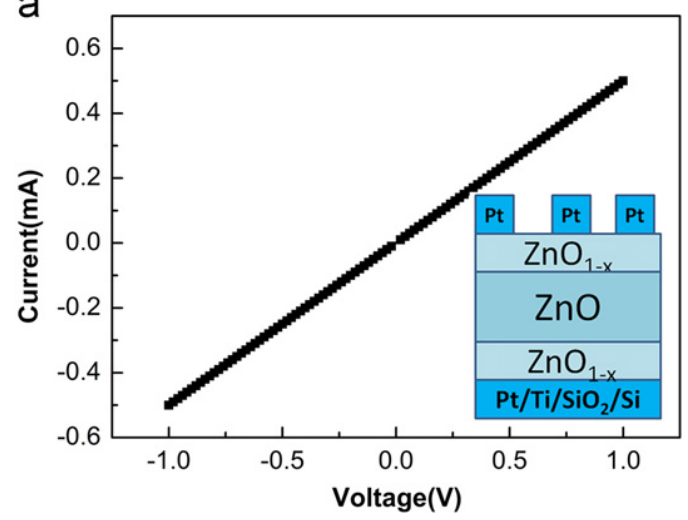

b

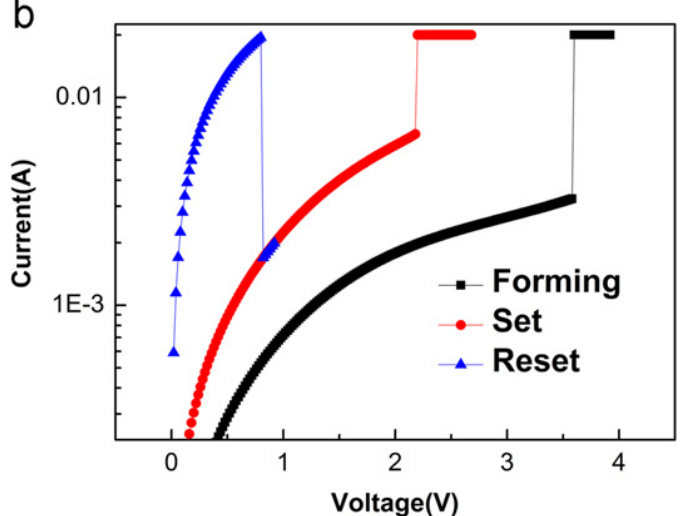

Fig. 3. (Color online) (a) The $I-V$ curves of the $\mathrm{Pt} / \mathrm{ZnO}_{1-x} / \mathrm{ZnO} / \mathrm{ZnO}_{1-x} / \mathrm{Pt}$ device in its pristine states. Inset is schematic configuration of stacked $\mathrm{Pt} / \mathrm{ZnO}_{1-x} / \mathrm{ZnO} / \mathrm{ZnO}_{1-x}$ Pt structure. (b) Forming and URS $I-V$ curves for the $\mathrm{Pt} / \mathrm{ZnO}_{1-x} / \mathrm{ZnO}_{\mathrm{ZnO}_{1-x}} / \mathrm{Pt}$ device.

fabricated the stacked $\mathrm{Pt} / \mathrm{ZnO}_{1-x} / \mathrm{ZnO} / \mathrm{ZnO}_{1-x} / \mathrm{Pt}$ devices to eliminate the Schottky interfaces. The schematic picture was shown in the inset of Fig. 3(a). Due to the Ohmic contact at $\mathrm{Pt} / \mathrm{ZnO}_{1-x}$ interface, the $\mathrm{Pt} / \mathrm{ZnO}_{1-x} / \mathrm{ZnO} / \mathrm{ZnO}_{1-x} / \mathrm{Pt}$ devices exhibit an Ohmic behavior [Fig. 3(a)] and have much lower $R_{\text {initial }}(2000 \Omega)$. URS behavior was still observed, as shown in Fig. 3(b). It indicates that the Schottky interface is not an essential condition for URS behavior. For the Pt/ZnO/Pt devices, the initial existed oxygen vacancies and the new generated oxygen vacancies would drift and accumulate at the cathode in the forming process, changing the cathode Schottky interface to Ohmic contact. After the oxygen vacancies filament formed, the anode Schottky interface was also changed to Ohmic contact and the device was switched to LRS.

In order to further investigate the effect of oxygen vacancy content on the URS characteristics of ZnO thin film memory devices, the $\mathrm{ZnO}$ films were annealed at vacuum $\left(600^{\circ} \mathrm{C}\right.$, $20 \mathrm{~min}$ ) to increase the oxygen vacancy content and annealed at oxygen atmosphere $\left(600^{\circ} \mathrm{C}, 40 \mathrm{~min}\right)$ to decrease the oxygen vacancy content. The oxygen annealed, vacuum annealed, and as prepared (unanealed) $\mathrm{ZnO}$ thin films are respectively mentioned as ZnO-Oxy, $\mathrm{ZnO}-\mathrm{Vac}$, and $\mathrm{ZnO}-\mathrm{As}$ in the following discussion.

Wide distribution of resistive switching parameters is considered as one of major obstacles for the application of RRAM $[7,23]$. The distribution of resistive switching parameters for the $\mathrm{Pt} / \mathrm{ZnO}$ Oxy/Pt, Pt/ZnO-Vac/Pt and Pt/ZnO-As/Pt devices was measured, as shown in Fig. 4(a)-(d). The data was obtained from 50 times continuous sweeping cycles. Compared with unannealed sample, the Pt/ZnO-Vac/Pt devices show narrower distribution of switching voltage while the $\mathrm{Pt} / \mathrm{ZnO}-\mathrm{Oxy} / \mathrm{Pt}$ devices exhibit wider, especially the set voltage. Importantly, the set voltage and reset voltage of Pt/ZnO-Vac/Pt device shows an evident window, which
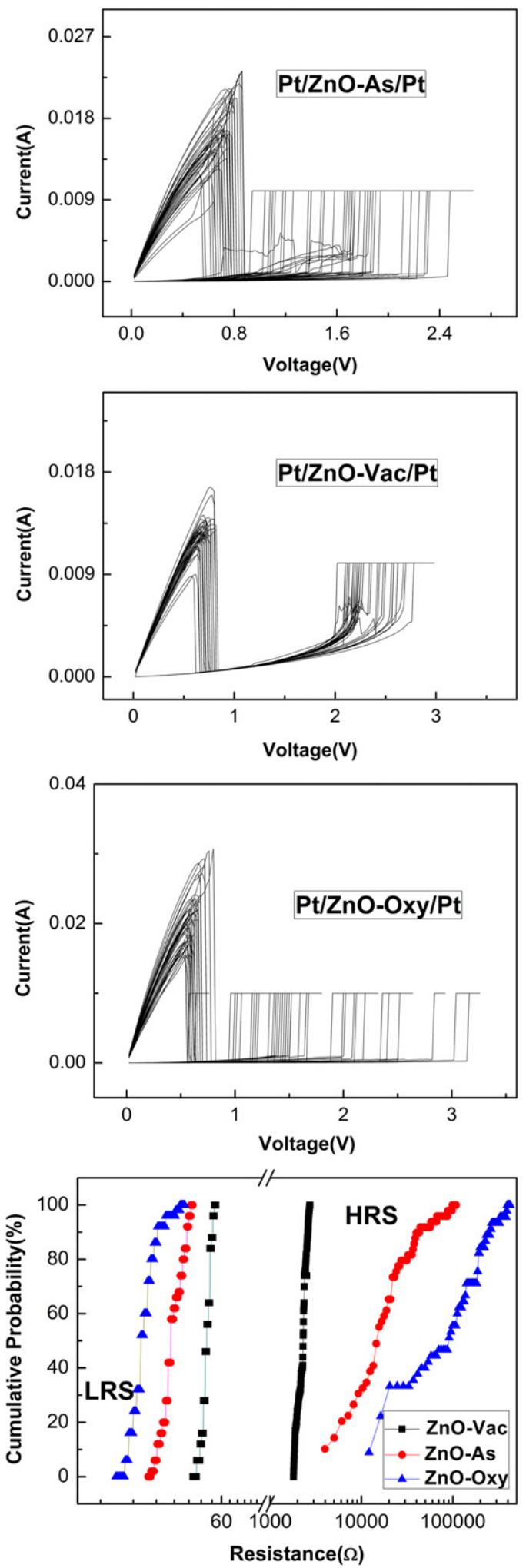

Fig. 4. (Color online) Measurement of $\mathrm{Pt} / \mathrm{ZnO}-\mathrm{As} / \mathrm{Pt}, \mathrm{Pt} / \mathrm{ZnO}-\mathrm{Vac} / \mathrm{Pt}$ and $\mathrm{Pt} / \mathrm{ZnO}$ Oxy/Pt devices for continuous 50 cycles in DC sweeping mode. (a), (b) and (c) Set and Reset Voltage distributions. (d) $R_{\text {off }}$ and $R_{\text {on }}$ distributions.

is essential to avoid wrong operation. Fig. 4(d) shows the distributions of $R_{\text {off }}$ and $R_{\text {on }}$. Although the ratio of $R_{\text {off }} / R_{\text {on }}$ is decreased for the $\mathrm{Pt} / \mathrm{ZnO}$-Vac/Pt device (higher $R_{\text {on }}$ and lower $R_{\text {off }}$ ), both fluctuations of $R_{\text {off }}$ and $R_{\text {on }}$ for the $\mathrm{Pt} / \mathrm{ZnO}-\mathrm{Vac} / \mathrm{Pt}$ devices are narrowed down greatly compared with $\mathrm{Pt} / \mathrm{ZnO}-\mathrm{Oxy} / \mathrm{Pt}$ and $\mathrm{Pt} / \mathrm{ZnO}-\mathrm{As} / \mathrm{Pt}$ devices. In 

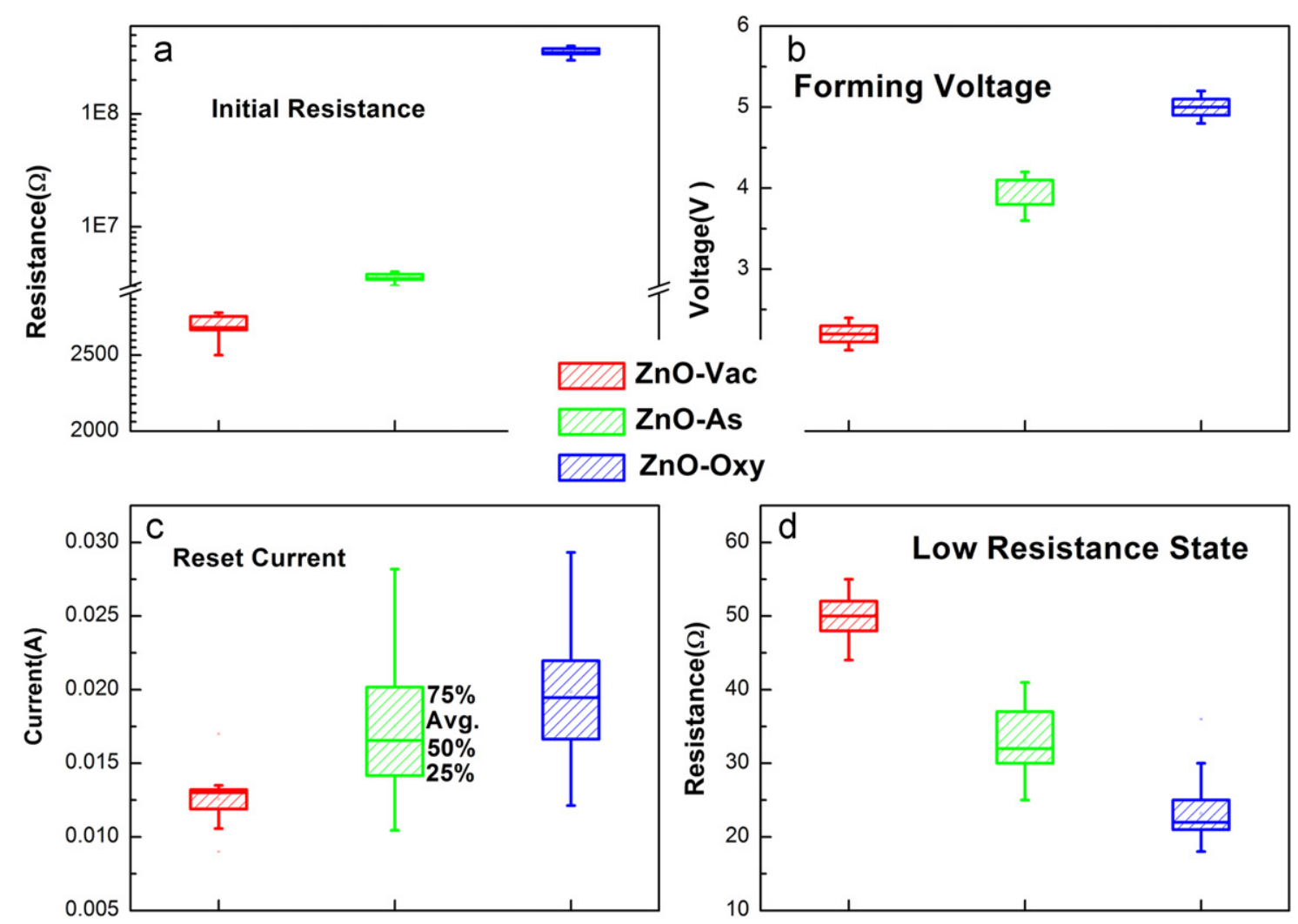

Fig. 5. (Color online) Statistics of resistive switching parameters in Pt/ZnO-As/Pt, Pt/ZnO-Vac/Pt and Pt/ZnO-Oxy/Pt devices, respectively.

a word, narrower distributions of switching parameters (set and reset voltage, $R_{\mathrm{HRS}}$ and $R_{\mathrm{LRS}}$ ) were obtained in the $\mathrm{Pt} / \mathrm{ZnO}-\mathrm{Vac} / \mathrm{Pt}$ devices.

The variation of URS switching parameters for Pt/ZnO-Oxy/Pt, $\mathrm{Pt} / \mathrm{ZnO}-\mathrm{Vac} / \mathrm{Pt}$, and $\mathrm{Pt} / \mathrm{ZnO}-\mathrm{As} / \mathrm{Pt}$ devices were shown in Fig. 5, each result was examined from measurements on 30 devices. As shown in Fig. 5(a), significantly reduced $R_{\text {initial }}(2500 \Omega$ ) was observed in Pt/ZnO-Vac/Pt devices and increased highly $R_{\text {initial }}$ $\left(5 \times 10^{8} \Omega\right)$ in the $\mathrm{Pt} / \mathrm{ZnO}-\mathrm{Oxy} / \mathrm{Pt}$ devices. Since oxygen vacancies in $\mathrm{ZnO}$ are known to act as n-type dopants, it is reasonable that the device with more oxygen vacancies shows a better conductivity. The forming voltage of these devices has the similar trend with that of $R_{\text {initial. }}$ As shown in Fig. 5(b), the Pt/ZnO-Oxy/Pt devices have the highest forming voltage which is about $4.9 \mathrm{~V}$; the $\mathrm{Pt} / \mathrm{ZnO}-\mathrm{As} / \mathrm{Pt}$ devices have a morderate value of $3.8 \mathrm{~V}$; while $\mathrm{Pt} / \mathrm{ZnO}-\mathrm{Vac} / \mathrm{Pt}$ devices have the lowest forming voltage among the three, which is about $2 \mathrm{~V}$. It is worth noting that the forming voltage of $2 \mathrm{~V}$ in Pt/ZnO-Vac/Pt devices is low enough and has the same magnitude with set voltage. In another word, the Pt/ZnOVac/Pt devices can initially switch from HRS without forming process. However, it should be noticed that if we continue to increase the annealing time at vacuum, the invalid storage points will increase dramatically due to large leakage current. Fig. 5(c) and (d) shows the variation of reset current and $R_{\text {on }}$. The Pt/ZnO-Vac/Pt devices show lower reset current and higher $R_{\text {on }}$, while the Pt/ZnO-Oxy/Pt devices exhibit higher reset current and lower $R_{\text {on }}$. Therefore, by increasing the oxygen vacancy content in the Pt/ZnO/Pt device, better URS properties (formingfree and lower reset current) could be obtained.

According to the existing switching mechanisms in $\mathrm{ZnO}$ thin films, a possible explanation for the improvement (vacuumannealed samples) and degradation (oxygen-annealed samples) of URS characteristics in $\mathrm{ZnO}$ thin film memory devices could be depicted as follows. The vacuum annealing will increase oxygen vacancy content and oxygen annealing will decreasing oxygen content. For the low oxygen vacancy content films (ZnO-Oxy), more new generated oxygen vacancies are required to form the filament in the forming process so it need a higher forming voltage. Besides, due to the large contact resistance at the two Schottky interfaces in the low oxygen vacancy content devices, the forming voltage would drop a lot at the Schottky interfaces and the switching layer is distributed a part of the forming voltage. So the Pt/ZnO-Oxy/Pt devices require a higher forming voltage to generate enough oxygen vacancies while Pt/ZnO-Vac/Pt devices demand lower forming voltage (even as low as the set voltage). Correspondingly, the small forming voltage will generate small size filaments and little numbers of filaments in $\mathrm{ZnO}$ matrix. This may be the cause of small $\mathrm{R}_{\text {on }}$ and reset current in Pt/ZnO$\mathrm{Vac} / \mathrm{Pt}$ devices, which means the small size filaments and little numbers of filaments require fewer quantity of heat to rupture them [24]. The small size filaments are easy to control [25] and fewer filaments could suppress random formation and rupture of filament for memory switching. So the $\mathrm{Pt} / \mathrm{ZnO}-\mathrm{Vac} / \mathrm{Pt}$ devices exhibited narrow distribution of switching parameters. Based on above results and analysis, controlling the initial oxygen vacancy content should be an effective way to enhance the URS characteristics.

\section{Conclusions}

In summary, the effect of oxygen vacancy content on unipolar resistive switching characteristics of $\mathrm{ZnO}$ thin film memory devices was investigated. The content of oxygen vacancy is not only a crucial factor that governs the appearance of URS behavior, but also has significant influence on the URS characteristics. This indicated that controlling the initial oxygen vacancy content was an effective method to enhance the URS performance. 


\section{Acknowledgments}

This work was financially supported by Major Program of National Natural Science Foundation of China (Grant No. 90922026), Major State Basic Research Development Program (Grant No. 2009CB623304), and National Natural Science Foundation of China (Grant No. 51072216).

\section{References}

[1] G.I. Meijer, Science 319 (2008) 1625.

[2] K. Shibuya, R. Dittmann, S.B. Mi, R. Waser, Adv. Mater. 22 (2010) 411.

[3] R. Waser, M. Aono, Nat. Mater. 6 (2007) 833.

[4] A. Sawa, Mater. Today 11 (2008) 28.

[5] R. Waser, R. Dittmann, G. Staikov, K. Szot, Adv. Mater. 21 (2009) 2632.

[6] X. Gao, Y.D. Xia, B. Xu, J.Z. Kong, H.X. Guo, K. Li, H.T. Li, H.N. Xu, K. Chen J.A. Yin, Z.G. Liu, J. Appl. Phys. 108 (2010) 074506.

[7] S.C. Chae, J.S. Lee, S. Kim, S.B. Lee, S.H. Chang, C. Liu, B. Kahng, H. Shin D.W. Kim, C.U. Jung, S. Seo, M.J. Lee, T.W. Noh, Adv. Mater. 20 (2008) 1154.

[8] R. Yang, X.M. Li, W.D. Yu, X.J. Liu, X. Cao, Q. Wang, L.D. Chen, Electrochem. Solid-State Lett. 12 (2009) H281.

[9] S.-L. Li, J. Li, Y. Zhang, D.-N. Zheng, K. Tsukagoshi, Appl. Phys. A: Mater. Sci. Process 103 (2011) 21.

[10] W. Shen, R. Dittmann, R. Waser, J. Appl. Phys. 107 (2010) 094506.
[11] J.S. Lee, S.B. Lee, S.H. Chang, L.G. Gao, B.S. Kang, M.J. Lee, C.J. Kim, T.W. Noh, B. Kahng, Phys. Rev. Lett. 105 (2010) 205701.

[12] B.J. Choi, D.S. Jeong S.K. Kim, C. Rohde, S. Choi, J.H. Oh, H.J. Kim, C.S. Hwang K. Szot, R. Waser, B. Reichenberg, S. Tiedke, J. Appl. Phys. 98 (2005) 033715

[13] W.Y. Chang, Y.C. Lai, T.B. Wu, S.F. Wang, F. Chen, M.J. Tsai, Appl. Phys. Lett. 92 (2008) 022110.

[14] D.H. Kwon, K.M. Kim, J.H. Jang, J.M. Jeon, M.H. Lee, G.H. Kim, X.S. Li, G.S. Park, B. Lee, S. Han, M. Kim, C.S. Hwang, Nat. Nanotechnol. 5 (2010) 148.

[15] M.J. Lee, S. Han, S.H. Jeon, B.H. Park, B.S. Kang, S.E. Ahn, K.H. Kim, C.B. Lee C.J. Kim, I.K. Yoo, D.H. Seo, X.S. Li, J.B. Park, J.H. Lee, Y. Park, Nano Lett. 9 (2009) 1476.

[16] J.J. Yang, M.D. Pickett, X.M. Li, D.A.A. Ohlberg, D.R. Stewart, R.S. Williams, Nat Nanotechnol. 3 (2008) 429.

[17] S. Lee, H. Kim, D.J. Yun, S.W. Rhee, K. Yong, Appl. Phys. Lett. 95 (2009) 262113.

[18] S. Lee, H. Kim, J. Park, K. Yong, J. Appl. Phys. 108 (2010) 076101.

[19] Q.N. Mao, Z.G. Ji, J.H. Xi, J. Phys. D,: Appl. Phys 43 (2010) 395104

[20] A. Shih, W.D. Zhou, J. Qiu, H.J. Yang, S.Y. Chen, Z.T. Mi, I. Shih, Nanotechnology 21 (2010) 125201.

[21] S. Baek, J. Song, S. Lim, Physica B 399 (2007) 101.

22] W.C. Chien, Y.C. Chen, E.K. Lai, Y.D. Yao, P. Lin, S.F. Horng, J. Gong, T.H. Chou, H.M. Lin, M.N. Chang, Y.H. Shih, K.Y. Hsieh, R. Liu, C.Y. Lu, IEEE. Electron Device Lett. 31 (2010) 126.

[23] J.H. Yoon, K.M. Kim, M.H. Lee, S.K. Kim, G.H. Kim, S.J. Song, J.Y. Seok, C.S. Hwang, Appl. Phys. Lett. 97 (2010) 232904.

[24] H.D. Lee, Y. Nishi, Appl. Phys. Lett. 97 (2010) 252107.

[25] M.J. Lee, C.B. Lee, D. Lee, S.R. Lee, J. Hur, S.E. Ahn, M. Chang, Y.B. Kim, U.I. Chung, C.J. Kim, IEEE. Electron Device Lett. 31 (2011) 725. 